\title{
Impact of cryopreservation on tetramer, cytokine flow cytometry, and ELISPOT
}

Holden T Maecker*1, James Moon ${ }^{2}$, Sonny Bhatia1, Smita A Ghanekar1, Vernon C Maino ${ }^{1}$, Janice K Payne ${ }^{3}$, Kristine Kuus-Reichel ${ }^{3}$, Jennie C Chang 3 , Amanda Summers ${ }^{4}$, Timothy M Clay ${ }^{4}$, Michael A Morse ${ }^{4}$, H Kim Lyerly ${ }^{4}$, Corazon DeLaRosa ${ }^{5}$, Donna P Ankerst ${ }^{2}$ and Mary L Disis ${ }^{5}$

\begin{abstract}
Address: ${ }^{1}$ BD Biosciences, San Jose, USA, ${ }^{2}$ Southwest Oncology Group Statistical Center at Fred Hutchinson Cancer Research Center, Seattle, USA, ${ }^{3}$ Beckman-Coulter, San Diego, USA, ${ }^{4}$ Departments of Surgery, Medicine, Pathology, and Immunology, and Duke Comprehensive Cancer Center, Duke University Medical Center, Durham, USA and ${ }^{5}$ Tumor Vaccine Group, Division of Oncology, University of Washington, Seattle, USA

Email: Holden T Maecker* - holden_maecker@bd.com; James Moon - jmoon@fhcrc.org; Sonny Bhatia - sonny_bhatia@bd.com; Smita A Ghanekar - smita_ghanekar@bd.com; Vernon C Maino - smaino@bd.com; Janice K Payne - jkpayne@beckman.com; Kristine KuusReichel - tkuus-reichel@beckman.com; Jennie C Chang - jchang@cenzone.com; Amanda Summers - amanda.bradshaw@duke.edu; Timothy M Clay - tim.clay@duke.edu; Michael A Morse - morse004@mc.duke.edu; H Kim Lyerly - lyerl001@mc.duke.edu;

Corazon DeLaRosa - meannie@u.washington.edu; Donna P Ankerst - donnap@fhcrc.org; Mary L Disis - ndisis@u.washington.edu

* Corresponding author
\end{abstract}

Published: 18 July 2005

BMC Immunology 2005, 6:17 doi:10.1 186/147/-2172-6-17
Received: 26 January 2005

Accepted: 18 July 2005

This article is available from: http://www.biomedcentral.com/I47I-2/72/6/17

(c) 2005 Maecker et al; licensee BioMed Central Ltd.

This is an Open Access article distributed under the terms of the Creative Commons Attribution License (http://creativecommons.org/licenses/by/2.0), which permits unrestricted use, distribution, and reproduction in any medium, provided the original work is properly cited.

\begin{abstract}
Background: Cryopreservation of PBMC and/or overnight shipping of samples are required for many clinical trials, despite their potentially adverse effects upon immune monitoring assays such as MHC-peptide tetramer staining, cytokine flow cytometry (CFC), and ELISPOT. In this study, we compared the performance of these assays on leukapheresed PBMC shipped overnight in medium versus cryopreserved PBMC from matched donors.
\end{abstract}

Results: Using CMV pp65 peptide pool stimulation or pp65 HLA-A2 tetramer staining, there was significant correlation between shipped and cryopreserved samples for each assay $(p \leq 0.00 \mathrm{I})$. The differences in response magnitude between cryopreserved and shipped PBMC specimens were not significant for most antigens and assays. There was significant correlation between CFC and ELISPOT assay using Pp65 peptide pool stimulation, in both shipped and cryopreserved samples ( $\mathrm{P}$ $\leq 0.00 \mathrm{I}$ ). Strong correlation was observed between CFC (using HLA-A2-restricted pp65 peptide stimulation) and tetramer staining $(\mathrm{P}<0.00 \mathrm{I})$. Roughly similar sensitivity and specificity were observed between the three assays and between shipped and cryopreserved samples for each assay.

Conclusion: We conclude that all three assays show concordant results on shipped versus cryopreserved specimens, when using a peptide-based readout. The assays are also concordant with each other in pair wise comparisons using equivalent antigen systems. 


\section{Background}

An increasing number of experimental vaccines are being developed for diseases in which cellular immunity is likely to be required for protection [1]. These include HIV [2], hepatitis C [3], malaria [4], and cancer [5]. In these settings, immunological monitoring of antigen-specific $\mathrm{T}$ cell responses is likely to be an important part of vaccine assessment [6-10]. Unfortunately, surrogate markers of protection have not been established for vaccines that induce cellular immunity, although correlations between $\mathrm{T}$ cell IFN $\gamma$ production and clinical responses have been reported in small numbers of patients $[11,12]$ and in mouse models [13-17].

Even in the absence of surrogate markers of protection, the degree to which vaccines can induce $T$ cell responses can be taken as a measure of immunogenicity, or potency, and as such can be used to compare different vaccine candidates. It is likely that inducing a particular level of antigen-specific $\mathrm{T}$ cell response to a vaccine will be necessary, though perhaps not sufficient, for vaccine efficacy of either prophylactic or therapeutic vaccines $[9,10]$.

Traditional assays of cellular immunity have been bulk assays, including proliferation assays measuring ${ }^{3} \mathrm{H}$-thymidine incorporation [18] or cytotoxicity assays measuring ${ }^{51} \mathrm{Cr}$ release [19]. These are increasingly being replaced by single-cell assays, such as MHC-peptide tetramer staining [20], cytokine flow cytometry (CFC) - also known as intracellular cytokine staining (ICS) [21,22], and enzymelinked immunospot (ELISPOT) [23]. These assays tend to be more quantitative, in that they report a fraction of $\mathrm{T}$ cells or PBMC that bind a particular MHC-peptide combination or that produce a particular cytokine in response to an antigen.

Comparisons of tetramer, CFC, and/or ELISPOT have been published [12,24-31], but the relative effect of PBMC cryopreservation on each of these assays has not been examined in a side-by-side fashion. It is known that cryopreservation can negatively impact functional responses [32-35], particularly to nominal antigens. One effect of cryopreservation appears to be the loss of antigen processing capability, as measured by a disproportionate loss of responses to protein antigens, as compared to peptides [36]. There is also a relationship between viability post-thawing and capacity for functional responses [37].

The method of cryopreservation can have a tremendous impact upon viability and function [37-39]. Nevertheless, some authors have reported equivalent results in ELISPOT for fresh and frozen samples, when using an optimized protocol [39-42]. For the present study, an optimized cryopreservation protocol was developed (Disis et al., manuscript submitted) [see Additional file 1]. Two factors that had a positive impact upon cell viability and recovery, and which were incorporated into this optimized protocol, included: (1) the use of human serum albumin as a protein source in the freezing medium, and (2) the use of warmed medium for initial dilution of cells after thawing.

Using this optimized cryopreservation protocol, the present study was conducted in order to determine: (1) the correlation of fresh and cryopreserved results for tetramer, CFC, and ELISPOT assays; (2) the sensitivity and specificity of each assay using CMV seropositive and CMV seronegative donors; and (3) the inter-assay correlations using fresh versus optimally cryopreserved cells. Fresh and cryopreserved PBMC from leukapheresed healthy donors were overnight shipped, in blinded fashion, to three different laboratories, each of which was an experienced practitioner of one of the three assays. These laboratories reported results for their assay to a statistical core, where the results were compiled and statistical analyses carried out.

\section{Results}

\section{Fresh versus cryopreserved assay correlations}

PBMC derived from leukapheresis of $20 \mathrm{CMV}$ seropositive and $21 \mathrm{CMV}$ seronegative donors were analyzed as fresh samples (overnight shipped) or frozen samples (cryopreserved then shipped on dry ice). Cells were processed and analyzed in a blinded fashion by tetramer staining, CFC, and ELISPOT. Representative data for each assay is shown in Figure 1. Correlations of fresh versus frozen data were performed, and are shown in Figure 2.

\section{Fresh versus frozen tetramer results}

20 HLA-A0201+ donors (12 CMV seropositive and 8 CMV seronegative) were analyzed by tetramer staining, using an HLA-A0201 tetramer loaded with CMV pp65 ${ }_{495-503}$ peptide. Both seropositive and seronegative donors were analyzed together to determine whether putative negative results were similar in fresh versus frozen assays, as well as putative positive results. Frequencies of tetramer ${ }^{+}$cells in fresh versus frozen samples from these donors were significantly correlated $(r=0.9,95 \%$ C.I.: $0.9-1.0 ; p<0.001)$ (Figure 2A). To be sure that this was not simply based upon the correlation of the negative results alone, the statistics were recalculated on CMV seropositive data only, and the correlation coefficient remained 0.9 (95\% C.I.: $0.7-1.0)$.

To determine the bias between fresh and frozen samples from the CMV seropositive donors, the frequency of tetramer ${ }^{+}$cells in frozen samples was subtracted from that of the respective fresh samples (Figure 2B). The median difference in responses was -0.008 (95\% C.I.: -0.2 to $0.07)$. The Wilcoxon signed-rank test was unable to detect a significant bias towards either sample type. 

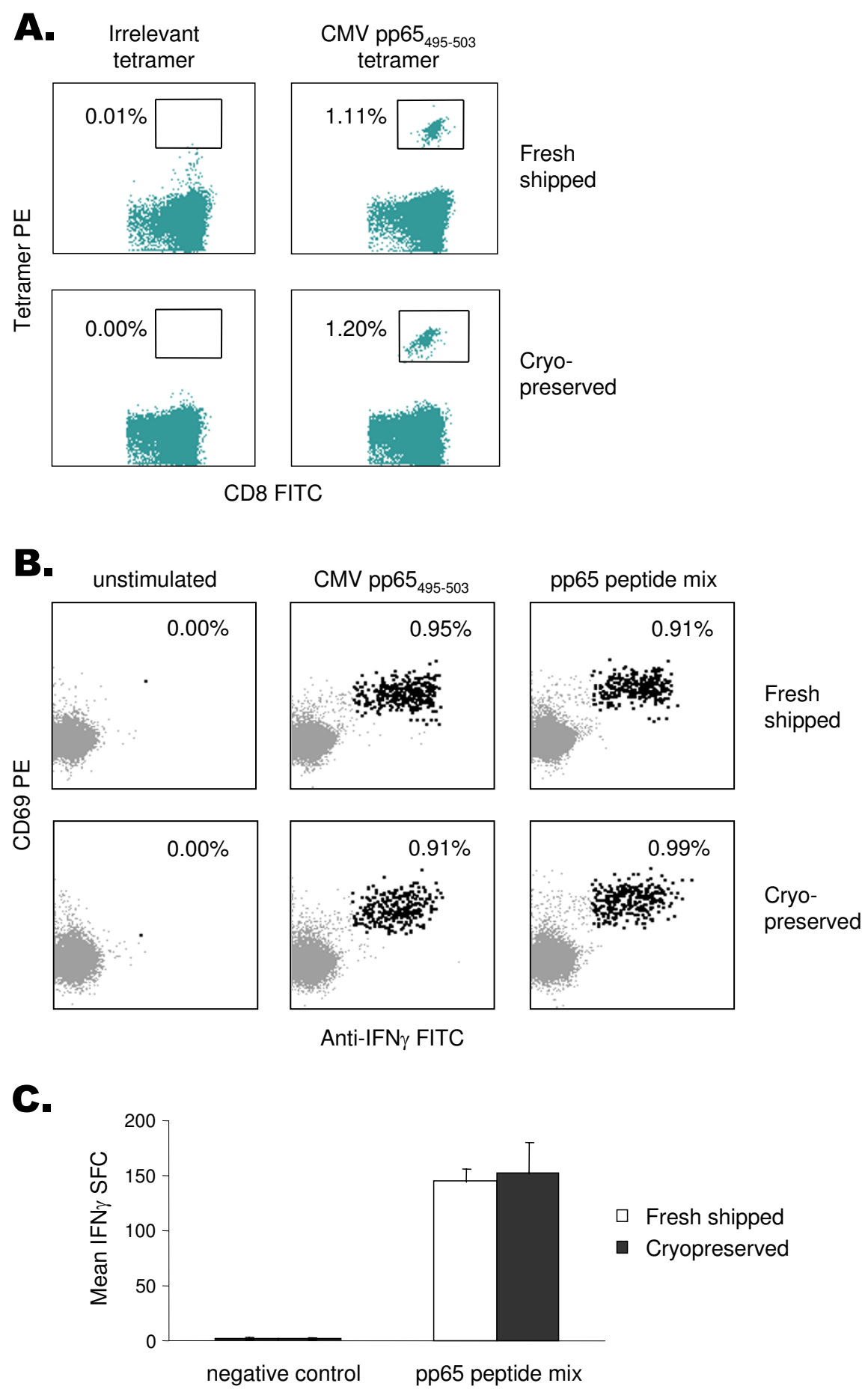

\section{Figure I}

Representative data from the three assays on the same CMV seropositive donor PBMC. (A) Tetramer staining after gating as described in the Methods. Background seen in staining of fresh cells with negative tetramer was caused by streptavidin-PE. Frozen cells were stained with a different lot of negative tetramer. (B) CFC staining after gating as described in the Methods. (C) ELISPOT data as analyzed on the Automated Reader System as described in the Methods. Error bars represent the S.D. of 6 replicates. 
A.

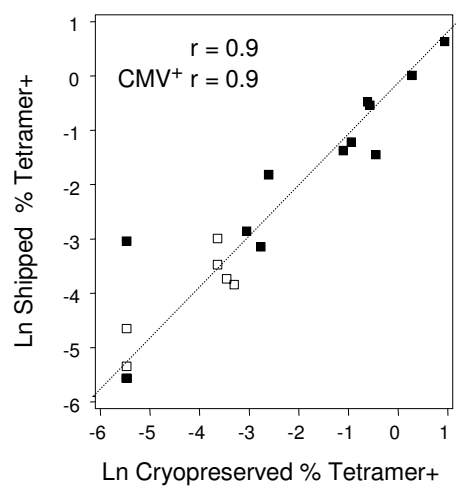

c.

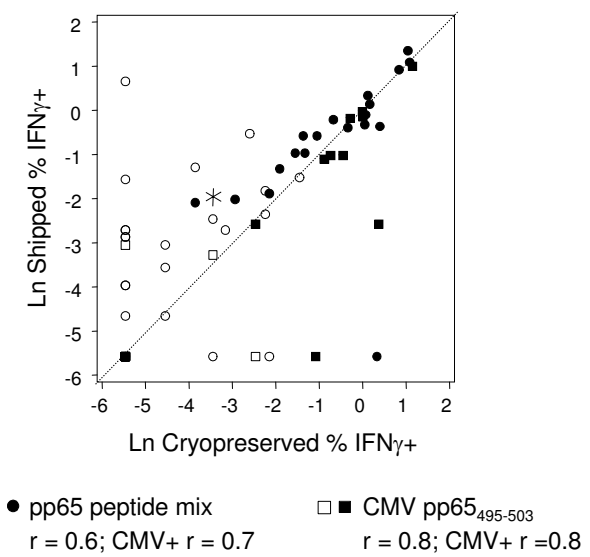

B.

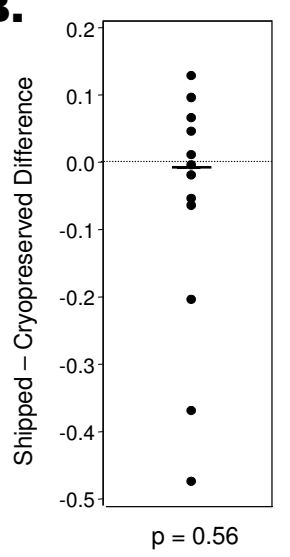

D.

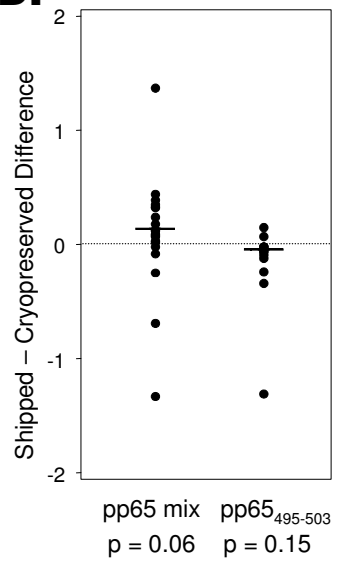

E.

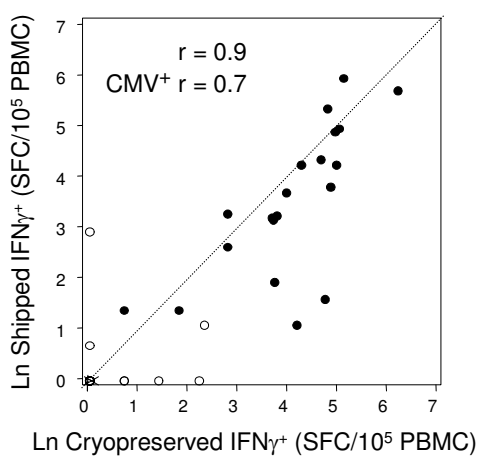

F.

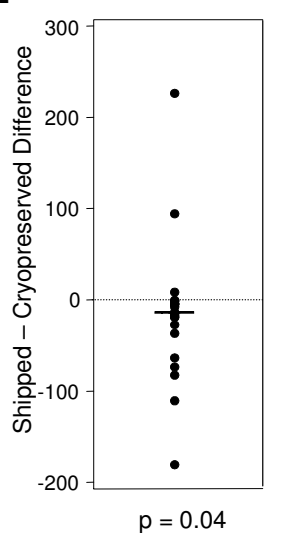

Figure 2

Correlation of fresh-shipped and cryopreserved samples in all three assays. (A, C, E) Correlation graphs of freshshipped versus cryopreserved PBMC samples for tetramer, CFC, and ELISPOT, respectively. Correlation coefficients ( $r$ ) are shown for all data as well as for CMV seropositive donors only. Open symbols represent CMV seronegative donors; closed symbols, seropositive donors (*, CMV serostatus unknown). The diagonal line represents the line of perfect agreement between the assays. (B, D, F) Within-donor differences are shown for fresh-shipped versus cryopreserved responses. Bars represent the median difference of all donors. All statistics are based on a natural logarithm transformation, which was done to better approximate a bivariate normal distribution. 


\section{Fresh versus frozen CFC}

$\mathrm{CD} 8^{+} \mathrm{T}$ cell IFN $\gamma$ production was measured by CFC using two different $\mathrm{CMV}$ antigens for stimulation: (1) a mixture of overlapping peptides corresponding to the CMV pp65 protein; and (2) the pp65 ${ }_{495-503}$ peptide. The former stimulus was used for comparison to ELISPOT, while the latter allowed comparison to tetramer staining. CFC responses in fresh and frozen PBMC samples from all donors correlated significantly with both antigens. The estimated correlation coefficient for CMV pp65 peptide mix stimulated samples was 0.6 (95\% C.I.: $0.4-0.8)(\mathrm{p}<0.001)$, and that for CMV-A2 peptide stimulated samples was 0.8 , $(95 \%$ C.I.: 0.6-0.8) ( $<0.001)$ (Figure $2 \mathrm{C})$. These coefficients did not change noticeably when only CMV seropositive data points were considered $(\mathrm{r}=0.7$ (95\% C.I.: $0.3-0.9)$ and 0.8 (95\% C.I.: 0.4-0.9), respectively). Positive correlation of fresh and frozen samples was also observed for SEB-stimulated samples $(\mathrm{r}=0.5, \mathrm{p}=0.002$; data not shown).

To determine a bias towards a particular sample type, the difference between responses of fresh and frozen samples from CMV seropositive donors were calculated (Figure 2D). The median difference in responses to CMV-A2 peptide was -0.04 (95\% C.I.: -0.22 to 0.00$)$ and the median difference to CMV pp65 peptide mix was 0.13 (95\% C.I.: 0.04-0.34). The Wilcoxon signed-rank test was unable to detect a significant bias towards either sample type stimulated with either of the two CMV antigens. However, there was a trend toward higher fresh responses to CMV pp65 peptide mix $(\mathrm{p}=0.06)$.

CFC responses to pp65 peptide mix and SEB in CD4+ $\mathrm{T}$ cells were also measured, and showed similar correlation between fresh and frozen samples $(r=0.6$ and 0.4 , respectively, with $\mathrm{p}<0.001$ for both stimuli) (data not shown).

\section{Fresh versus frozen ELISPOT}

IFN $\gamma$ producing cells were measured by ELISPOT using either CMV pp65 peptide mix or SEB, and enumerated in replicates of 6 wells. The responses of fresh and frozen samples from all donors correlated significantly for pp65 peptide mix stimulation $(\mathrm{r}=0.9$, 95\% C.I.: $0.8-0.9$; $\mathrm{p}<$ 0.001) (Figure 2E). The correlation coefficient was somewhat lower when only CMV seropositive data points were considered ( $r=0.7$, 95\% C.I.: 0.4-0.9). Interestingly, no significant correlation was observed for SEB activated samples (data not shown).

Fresh versus frozen bias was determined by subtracting pp65 peptide mix responses of frozen samples from their respective fresh samples, for $\mathrm{CMV}$ seropositive donors (Figure 2F). The median difference in responses was -12.5, (95\% C.I.: -2 to -34 ). There was a significant bias toward higher responses in frozen samples $(\mathrm{p}=0.04)$.

\section{Sensitivity and specificity measurements}

To further characterize the relative performance of the three assays, they were examined for their ability to predict CMV serostatus, using fresh and frozen PBMC. Sideby-side dot plots (Figure 3) show the results on CMV seronegative versus seropositive donors for each assay.

Sensitivity was defined as the proportion of CMV seropositive donors correctly identified using a particular cutoff, while specificity was defined as 1 - the false positive rate at that cutoff. These values vary inversely with each other, depending upon the cutoff value used to classify results as positive or negative. To quantitatively compare assay performance, the highest attainable specificity for a sensitivity of $\geq 90 \%$ (if achievable) was reported for each assay (Table 1).

\section{Sensitivity and specificity of tetramer staining}

For tetramer staining on fresh samples (Figure 3A), the median number of tetramer ${ }^{+}$cells was $0.02 \%$ for $\mathrm{CMV}$ seronegative donors, and $0.26 \%$ for CMV seropositive donors ( $\mathrm{n}=8$ and 12, respectively). For frozen samples (Figure 3B), these medians were $0.01 \%$ and $0.26 \%$, respectively.

A positive/negative cutoff of $0.03 \%$ for fresh samples and $0.02 \%$ for cryopreserved samples was determined as described above. Neither sample type yielded 100\% sensitivity and specificity (Table 1). Additionally, there was no consistent change in sensitivity and specificity between fresh and cryopreserved data sets.

\section{Sensitivity and specificity of CFC}

For fresh CFC samples (Figure 3C), the median response was $0.07 \%$ for seronegative donors and $0.71 \%$ for seropositive donors ( $\mathrm{n}=20$ and 21, respectively). For frozen samples (Figure 3D), these medians were $0.01 \%$ and $0.58 \%$, respectively.

For CMV pp65 peptide mix stimulation, positive/negative cutoff values of $0.13 \%$ for fresh samples and $0.05 \%$ for frozen samples were calculated as described above. For CMV pp65 $5_{495-503}$ peptide stimulation, the cutoffs were $0.08 \%$ for both fresh and frozen samples. Again, none of these assays reached $100 \%$ sensitivity and specificity (Table 1). There was also no consistent change in sensitivity and specificity between fresh and cryopreserved data sets.

\section{Sensitivity and specificity of ELISPOT}

For fresh ELISPOT samples (Figure 3E), the median number of SFC was 0 for seronegative donors and 34 for seropositive donors. For frozen samples (Figure 3F), these medians were 1 and 67, respectively. These numbers 


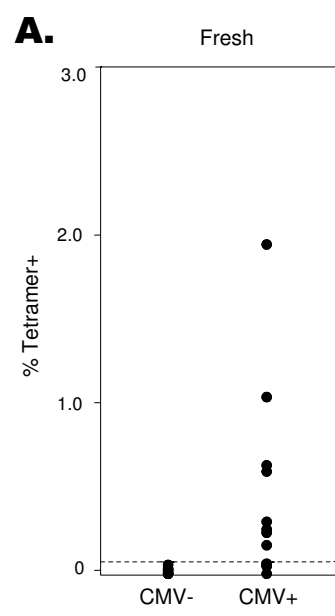

C.

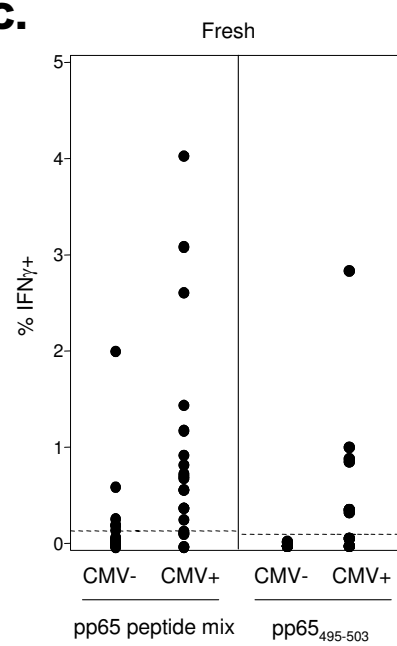

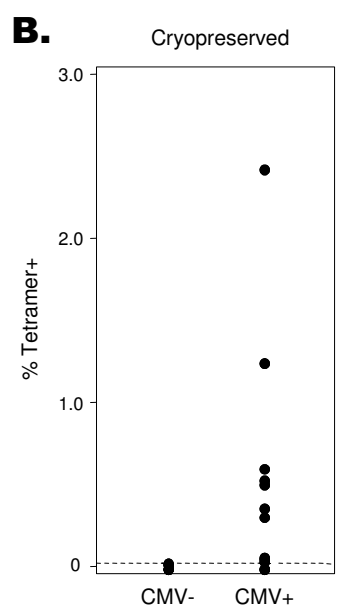

D.
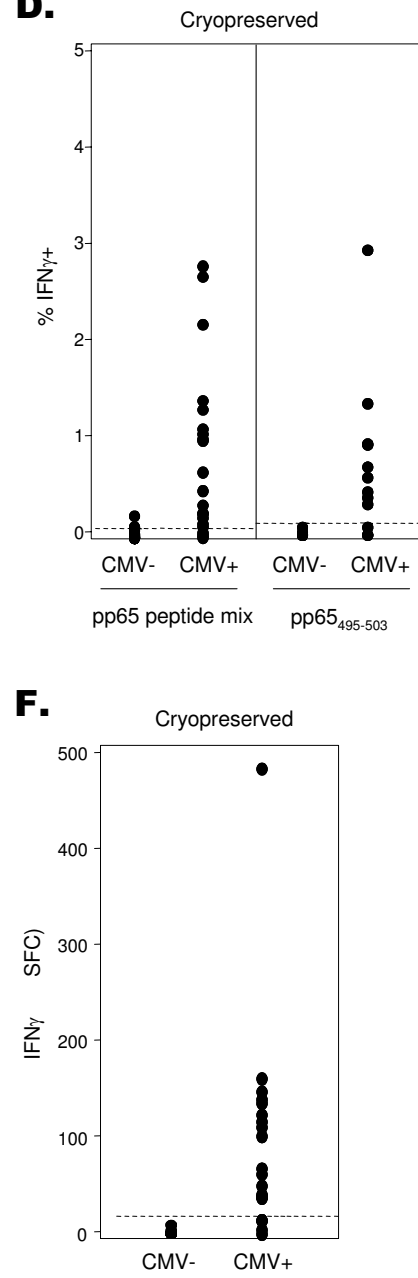

Figure 3

Results of the three assays on CMV seronegative versus seropositive donors. (A and B) Tetramer results on freshshipped and cryopreserved PBMC samples, respectively. (C and D) CFC results on fresh-shipped and cryopreserved PBMC samples, respectively. (E and F) ELISPOT results on fresh-shipped and cryopreserved PBMC samples, respectively. The dotted line represents the suggested cutoff based upon maximum specificity for sensitivity $\geq 90 \%$, or that which obtains maximum sensitivity if maximum sensitivity $<90 \%$. 
Table I: Cutoffs, sensitivity, and specificity from ROC curves

\begin{tabular}{lllllll}
\hline Assay & Antigen & Sample Type & Cutoff Point & Sensitivity & Specificity & Area Under ROC Curve $^{2}$ \\
\hline \multirow{2}{*}{ Tetramer (\%+) } & CMV pp65 A2 peptide & Fresh & 0.05 & $92 \%$ & $88 \%$ & $0.906+/-0.076$ \\
& & Cryo. & 0.02 & $83 \%$ & $100 \%$ & $0.875+/-0.086$ \\
& & & & & \\
& CMV pp65 peptide mix & Fresh & 0.13 & $90 \%$ & $71 \%$ & $0.819+/-0.075$ \\
CFC $(\%+)$ & & Cryo. & 0.05 & $90 \%$ & $76 \%$ & $0.920+/-0.046$ \\
& CMV pp65 A2 peptide & Fresh & 0.08 & $75 \%$ & $100 \%$ & $0.844+/-0.084$ \\
& & Cryo. & 0.08 & $83 \%$ & $88 \%$ & $0.891+/-0.074$ \\
\hline \multirow{2}{*}{ ELISPOT (\# SFC) } & CMV pp65 peptide mix & Fresh & 4 & $95 \%$ & $94 \%$ & $0.982+/-0.018$ \\
& & Cryo. & 16 & $90 \%$ & $100 \%$ & $0.985+/-0.015$ \\
\hline
\end{tabular}

'Cut-off is that which achieves maximum specificity for sensitivity $\geq 90 \%$, or that which obtains maximum sensitivity if maximum sensitivity $<90 \%$.) 2 Values are given $+/$ - standard error.

reiterate the bias in ELISPOT toward higher responses in frozen versus fresh samples in this study.

When positive/negative cutoff values were calculated as above, these were 4 SFC for fresh samples and 16 SFC for frozen samples. As with the other assays, 100\% sensitivity and specificity was not reached (Table 1). Also, there was no consistent change in sensitivity and specificity between fresh and cryopreserved data sets.

Another way to compare sensitivity and specificity between assays and formats is to plot the sensitivity versus false positive rate in an ROC plot, and then calculate the area under this curve. The greater the area, the greater the ability of the assay to discriminate positive from negative samples. In comparing these areas (Table 1), no statistically significant differences were found between fresh and frozen samples for any of the assays, or between CFC and ELISPOT, or CFC and tetramer (all p values $>0.05$ ). This is despite the fact that tetramer and CFC results were calculated only for defined subsets of cells, whereas all PBMC were used in ELISPOT. Better discrimination might be obtained for $\mathrm{CFC}$ if $\mathrm{CD} 4^{+} \mathrm{T}$ cell responses were also included, or for tetramer if class II and/or additional class I epitope tetramers had been used. In fact, when CFC responses for pp65 peptide mix were recalculated to include all IFN $\gamma^{+} \mathrm{PBMC}$, not just $\mathrm{CD}^{+} \mathrm{T}$ cells, the area under the ROC curve was, on average, higher ( 0.890 for fresh, 0.915 for frozen PBMC), but still not significantly different from ELISPOT.

\section{Inter-assay correlations}

Two-way correlations were performed between tetramer staining and CFC, and between CFC and ELISPOT (Figure 4). CMV pp65 $5_{495-503}$-specific responses obtained using CFC were compared to HLA-A0201 pp65 $5_{495-503}$ tetramer staining for all 20 HLA-A0201+ donors in the study (12 CMV seropositive, 8 CMV seronegative). CMV pp65 pep- tide mix-specific responses obtained by CFC and ELISPOT were compared for all $20 \mathrm{CMV}$ seropositive and $21 \mathrm{CMV}$ seronegative donors in the study.

\section{Tetramer staining versus CFC}

These assays correlated significantly with each other for both fresh and frozen samples (Figures $4 \mathrm{~A}$ and $4 \mathrm{~B}$ ). The estimated correlation coefficient was 0.9 for both fresh and frozen samples (95\% C.I.: $0.8-1.0$ for both) (p < 0.001 for both). These were the strongest inter-assay correlations observed in this study.

\section{CFC versus ELISPOT}

A significant correlation between these two assays was observed using both fresh and frozen PBMC samples (data not shown). The estimated correlation coefficient was $0.5(95 \%$ C.I.: $0.2-0.7)(\mathrm{p}=0.001)$ for fresh samples, and 0.7 (95\% C.I.: $0.5-0.8)(\mathrm{p}<0.001)$ for frozen samples. However, when only CMV seropositive donors were considered, the $\mathrm{p}$ values became non-significant for both fresh and frozen samples. Thus, CFC and ELISPOT were less tightly correlated than tetramer and CFC. This is in agreement with another published report comparing ELISPOT and CFC [29].

The scales and readouts of CFC and ELISPOT are very different (\%IFN $\gamma^{+} \mathrm{CD} 8^{+} \mathrm{T}$ cells versus SFC per $\left.10^{5} \mathrm{PBMC}\right)$. To correct for these differences, the $\mathrm{CFC}$ results were expressed as the total number of IFN $\gamma^{+}$cells per $10^{5} \mathrm{PBMC}$, without gating on $\mathrm{CD} 3$ or $\mathrm{CD} 8$. This mimicked the readout of the ELISPOT assay, which reported positive events per $10^{5} \mathrm{PBMC}$ (the number of cells plated in each ELISPOT well). The estimated correlation coefficients under these conditions were 0.7 for both fresh $(95 \% \mathrm{CI}$ : $0.4-0.8$ ) and frozen (95\% CI: 0.5-0.8) samples ( $\mathrm{p}<$ 0.001 both) (Figure 4C and 4D). When only CMV seropositive samples were considered, the correlation coefficients became 0.8 (95\% CI: 0.5-0.9) and 0.4 (95\% 
A.

Fresh-Shipped

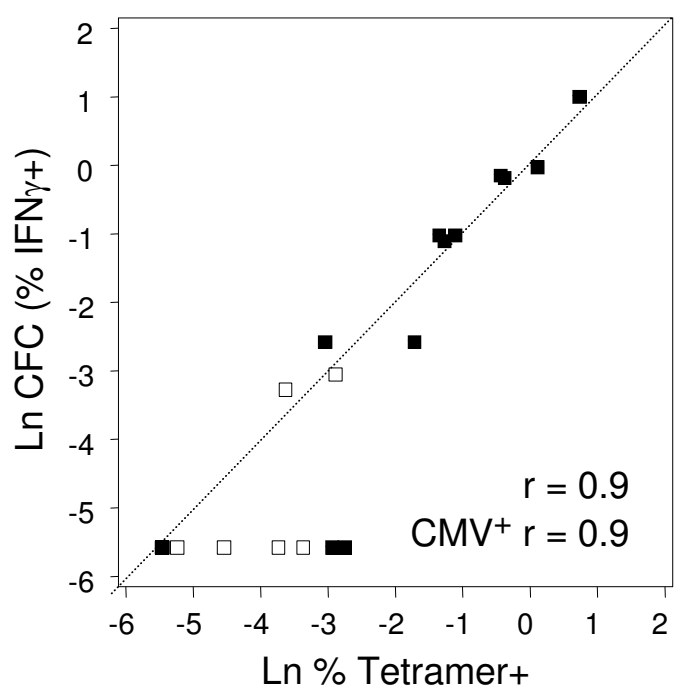

C.

Fresh-Shipped

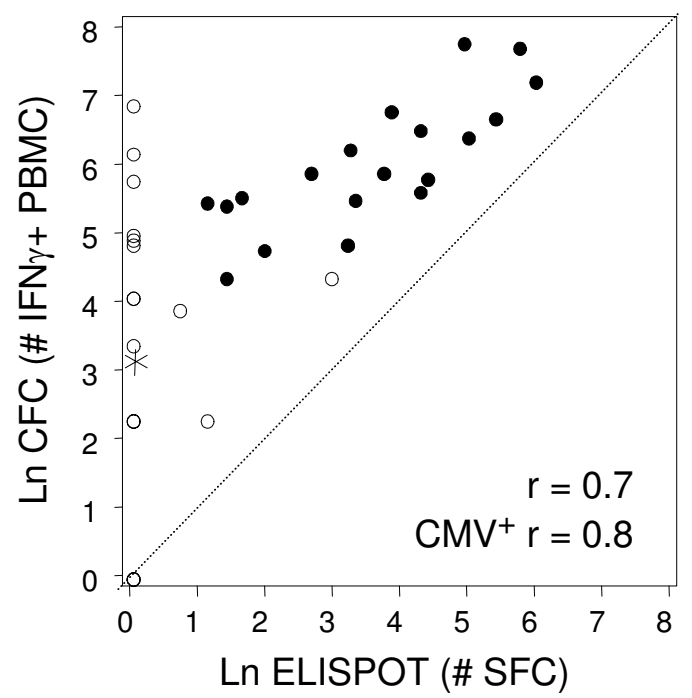

B.

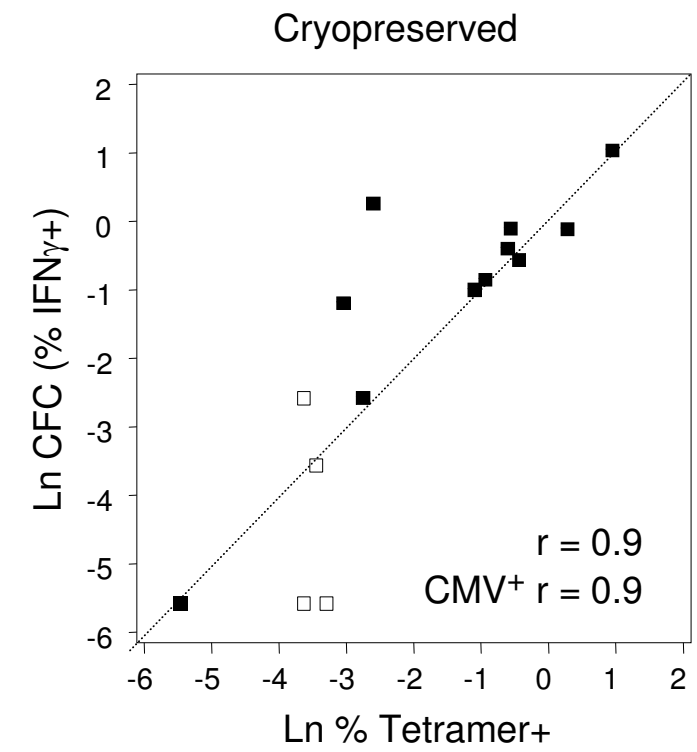

D.

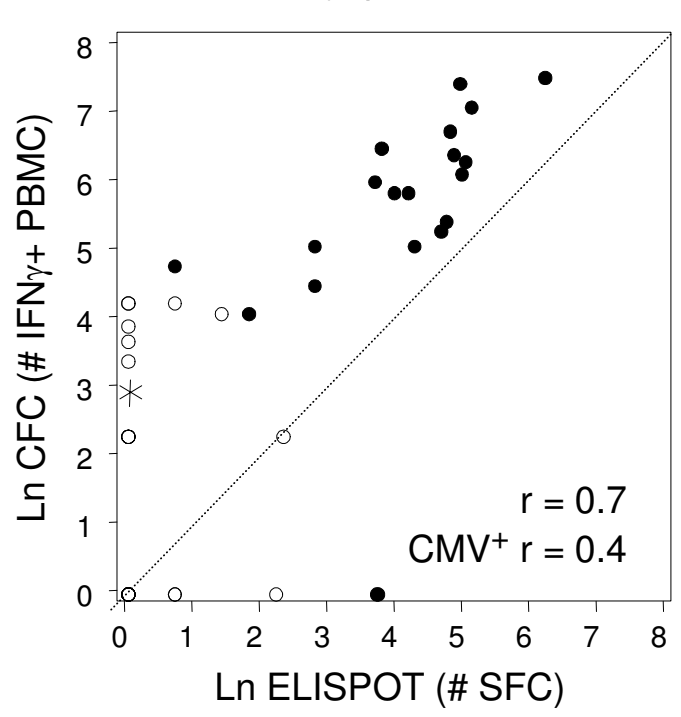

\section{Figure 4}

Inter-assay correlations. (A and B) Correlation of tetramer staining and CFC in fresh-shipped and cryopreserved PBMC samples, respectively. ( $C$ and $D$ ) Correlation of ELISPOT and CFC in fresh-shipped and cryopreserved PBMC samples, respectively, with CFC results reported as number of IFN $\gamma^{+}$cells per $10^{5}$ PBMC. In panels C-D, the mean of 6 replicates is shown for all ELISPOT data. Correlation coefficients ( $r$ ) are shown for all data as well as for CMV seropositive donors only. Open symbols represent CMV seronegative donors; closed symbols, seropositive donors (*, CMV serostatus unknown). The diagonal line represents the line of perfect agreement between the assays. 
Table 2: Summary of assay characteristics

\begin{tabular}{cccccc}
\hline Assay & Type of assay & Readout & Fresh to frozen correlation & Sensitivity and specificity' & Inter-assay correlations \\
\hline Tetramer & Phenotypic & 4-color flow cytometry & $r=0.9$ & $>70 \%^{2}$ & $r=0.9$ \\
CFC & Functional & 4-color flow cytometry & $r=0.6(\mathrm{CMV})$ & $>70 \%^{2}$ & $r=0.9$ \\
& & & $r=0.4(\mathrm{SEB})$ & $>90 \%$ & $r=0.7$ \\
ELISPOT & Functional & Plate reader & $r=0.6(\mathrm{CMV})$ & $\mathrm{NS}(\mathrm{SEB})$ & \\
& & & & & \\
\hline
\end{tabular}

'For both fresh and frozen samples with all peptide-based stimuli.

2Potentially higher if multiple tetramers or CD4 and CD8 responses are considered.

CI: $0.0-0.7$ ), respectively $(p<0.001$ and $p=0.06$, respectively). Thus, expression of the CFC results in this format appeared to improve the correlation. This may reflect the response of non-CD8 ${ }^{+}$cells in these assays. Note also that when CFC results were plotted in this way, there were on average several-fold higher responses with CFC versus ELISPOT (as represented by most points being above the diagonal in Figures 4C and 4D).

\section{Discussion}

This study represents a comprehensive analysis of the effect of cryopreservation (using an optimized cryopreservation protocol) on tetramer, CFC, and ELISPOT assays using peptide-based antigens. Each assay was individually optimized by a laboratory experienced in that technique, to ensure the best possible performance for each. For example, costimulatory antibodies (CD28 and CD49d) were used in CFC but not ELISPOT, despite the fact that addition of CD28 antibody can improve ELISPOT sensitivity [43]. In our hands, occasional donors developed unacceptably high ELISPOT backgrounds ( $>100$ spots per $10^{6}$ PBMC) with the use of CD28 costimulation (data not shown), so it was not used for that assay, although it was used for CFC. While there are shortcomings of this study design, we felt that this provided the fairest and most robust way to compare these assays. The assays were compared by correlation of results for fresh and frozen samples; by analyzing sensitivity and specificity of each assay on fresh and frozen samples; and by determining interassay correlations using fresh and frozen samples. The overall findings are summarized in Table 2.

None of the three assays showed a significant reduction of signal in frozen cells relative to fresh cells. The fresh-tofrozen correlation was strongest for tetramer staining, which does not rely on cell function, then CFC and ELISPOT. Compared to CMV responses, SEB responses were less well correlated in fresh and frozen samples using CFC, and not at all correlated using ELISPOT. The reasons for this are not clear; however, they may stem from the relative affinities of $T$ cells responding to CMV peptides versus SEB. It is known that $\mathrm{T}$ cells bearing a number of different
TCR V $\beta$ sequences can participate, to varying degrees, in the SEB response. The participation of different V $\beta$ families is related to their affinity for SEB. Low affinity V $\beta$ responses may be preferentially lost upon cryopreservation. The differential representation of these $V \beta$ subsets in different donors may thus lead to inconsistencies in the correlation of fresh to cryopreserved responses for SEB. $\mathrm{CMV}$ responses may be of generally uniform and higher affinity, as suggested by their typically bright, clustered IFN $\gamma$ staining (compared to SEB responses, where IFN $\gamma$ staining tends to be more of a smear). If this is true, it may also suggest that other low-affinity responses, such as those to tumor antigens, may be more susceptible to loss upon cryopreservation; this needs to be tested.

Rather than compare cryopreserved PBMC to fresh, sameday activated PBMC, the former were compared to fresh, overnight-shipped PBMC from leukapheresed donors. Since some functional degradation undoubtedly occurs with overnight shipping, this is not ideal in terms of assessing the total signal loss due to cryopreservation. However, the reality of large clinical studies is that PBMC will in all likelihood be cryopreserved and/or shipped overnight to a laboratory that does immunological monitoring. Thus, comparison of these two conditions represents a comparison of two likely scenarios for handling of PBMC samples in clinical trials. The current results imply that there is unlikely to be a pronounced difference in results with any of the three assays when using either of these conditions. It is unknown whether a detectable loss of signal would be observed if PBMC were subjected to both overnight shipping and then cryopreservation. Of course, all of these data assume that reasonable care is taken in sample cryopreservation and shipping, which were optimized for this study (Disis et al., manuscript submitted). Also, the stability of healthy donor cells, as used in this study, may be superior to those from certain disease states, e.g., HIV or tumor patients. Finally, the use of shipped PBMC (rather than whole blood) may have improved the results seen in this study; thus our results should not be taken as indicative of what would be achieved if whole blood samples were shipped overnight. 
Because this study used peptide-based antigens (and SEB), drastic loss of functional responses as reported for wholeprotein antigens [36] were not seen. The current results should not be interpreted to apply to non-peptide antigens, since antigen-processing capabilities are preferentially lost upon cryopreservation.

We defined sensitivity and specificity on the basis of reactivity with donors who were CMV seropositive, and lack of reactivity with donors who were CMV seronegative. This comparison is not ideal, since there are reports of non-correlation of serological and T cell responses to CMV [44]. In particular, assays examining a single epitope response (e.g., tetramer and CFC for pp65 $495-503$ ) may underestimate $\mathrm{CMV}$ responders, due to immunodominance hierarchies [45]. HLA-A2-restricted responses to pp65 $5_{495-503}$ are known to be suppressed in individuals co-expressing HLA-B7 [46], and such individuals were not excluded from this study. However, CFC assays using pp65 peptide mix were found in at least one previous study to differentiate $\mathrm{CMV}$ seropositive and seronegative donors with $100 \%$ sensitivity and specificity, although the sample size was small (15 seropositive and 14 seronegative donors) [47]. All three assays were recently compared in a study of fresh PBMC from $21 \mathrm{CMV}$ seropositive and $20 \mathrm{CMV}$ seronegative healthy donors, with a sensitivity of $87.5 \%$ and specificity of $100 \%$ for each assay [48].

None of the three assays attained 100\% sensitivity and specificity using either fresh or cryopreserved PBMC in the present study. ELISPOT, especially on cryopreserved PBMC, showed slightly greater sensitivity (for specificity $\geq 90 \%$ ) than did CFC or tetramer (although the difference was not statistically significant). This was partly due to the reactivity of one or two seronegative donors in the CFC and tetramer assays. This reactivity was more pronounced in the assays with fresh PBMC, but was still present in the cryopreserved PBMC from the same donors. In the case of CFC, the cryopreserved PBMC assay was repeated on additional cells and still showed a similar level of reactivity, suggesting that it was not due to a technical error. It is possible that these donors represented true discordant responses between serological and cellular assays.

The quantitative comparison of tetramer and CFC resulted in the tightest correlation. This could be related to the fact that both of these assays use the same readout platform (flow cytometry). The correlation of CFC and ELISPOT was less precise, and was not statistically significant when CMV seronegative donors were excluded. The correlation appeared tighter when CFC results were expressed as a proportion of all PBMC. This could be due to variable proportions of $\mathrm{CD} 4^{+} \mathrm{T}$ cells contributing to the response to pp65 peptide mix. It is also possible that non-T cells con- tribute to this response, although this was not directly assessed in this study.

\section{Conclusion}

We conclude that tetramer, CFC, and ELISPOT assays can be performed on optimally cryopreserved PBMC with minimal or no loss of signal when compared to fresh, overnight-shipped PBMC. The assays correlate significantly in direct comparisons using the same antigen systems, whether fresh or cryopreserved PBMC are used. The strongest correlations of fresh and cryopreserved PBMC are seen with tetramer and CFC assays; and these two assays also correlate most strongly with each other. All three assays showed roughly similar sensitivity and specificity in discriminating CMV seropositive from seronegative donors. The strong correlation of tetramer and CFC assays in fresh and cryopreserved cells, along with their multiparameter information content, make them ideal choices for immune monitoring assays.

\section{Methods}

\section{PBMC isolation and processing}

PBMC from leukapheresis (obtained from healthy donors without cytokine mobilization) were isolated using Ficoll gradient separation. Briefly, $5 \mathrm{ml}$ of leukapheresis product were aliquoted into $50 \mathrm{ml}$ conical tubes (BD Falcon, Franklin Lakes, NJ) washed once by adding HBSS (Gibco Invitrogen Corporation, Grand Island, NY) and centrifuged for 10 minutes at $280 \times \mathrm{G}$. The pelleted cells were resuspended and $40 \mathrm{ml}$ of HBSS were added. Ten $\mathrm{ml}$ of Ficoll Paque (Amersham Biosciences, Piscataway, NJ) were carefully underlayed and the tubes centrifuged at $400 \times \mathrm{G}$ for 40 minutes. The buffy coat was collected and washed twice with HBSS. Viability was assessed using $0.4 \%$ Trypan blue (Sigma, St. Louis, MO). For fresh-shipped specimens, $2 \times 10^{7}$ viable lymphocytes were resuspended in $50 \mathrm{ml} \mathrm{RPMI}+10 \%$ fetal bovine serum and shipped overnight at ambient temperature in a $50 \mathrm{ml}$ conical tube packed in an insulated foam container. Fresh-shipped PBMC were centrifuged as soon as received and the assays set up as described below.

\section{Cryopreservation [see Additional file I]}

To cryopreserve PBMC, $2 \mathrm{X}$ freezing media was first prepared, containing 20\% DMSO in RPMI (Sigma Chemical Co., St. Louis, MO) containing 12.5\% human serum albumin (HSA) (Gemini Bioproducts, Woodland, CA), and cooled on ice for a minimum of 30 minutes. Ficolled PBMC at $2 \times 10^{7}$ viable lymphocytes $/ \mathrm{ml}$ were resuspended in cooled RPMI $+12.5 \%$ HSA with no DMSO. An equal volume of chilled $2 \mathrm{X}$ freezing media was added to the cell suspension dropwise, while gently swirling the tube. One $\mathrm{ml}$ of this cell suspension was aliquoted into each cryovial (Sarstedt, Inc., Newton, NC). Once aliquoted, cryovials were placed on ice and then transferred into a freezing 
container (Nalgene, Rochester, NY), and stored at $-80^{\circ} \mathrm{C}$ for 24 hours. Cryovials were then transferred into liquid nitrogen for long-term storage. After 30 days, cryovials were overnight shipped on dry ice to the recipient laboratories.

\section{Thawing [see Additional file I]}

Cryopreserved $\mathrm{PBMC}$ were stored at $-80^{\circ} \mathrm{C}$ until thawing to set up the assays. Cryopreserved cells were thawed and slowly diluted with $8 \mathrm{ml}$ of warm RPMI $+10 \%$ fetal bovine serum+antibiotics (CRPMI-10, all components from Sigma). The cells were centrifuged for 7 minutes at $250 \times$ $G$, then resuspended as described below for each assay. Viability and recovery were checked using Trypan blue, and were $>80 \%$ and $>50 \%$, respectively, in all samples.

\section{MHC class I-peptide tetramer staining}

Fresh and frozen PBMC from $12 \mathrm{CMV}$ seropositive and 8 CMV seronegative patients were screened with MHC tetramer composed of HLA-A*0201 monomers carrying the CMV pp65 ${ }_{495-503}$ peptide epitope (NLVPMVATV). For flow cytometry analysis, the Multiple Antibody Single Color protocol (iMASC, Beckman Coulter Inc., Fullerton, CA) was used. Briefly, ten $\mu \mathrm{l}$ each of CD4, CD13, and CD19 antibodies conjugated to PE-Cy5 (PC5) were added to sample tubes in order to exclude CD4 T cells, granulocytes, and B cells from analysis. In addition, $10 \mu \mathrm{l}$ of CD8 FITC and $10 \mu \mathrm{l}$ tetramer PE were added, followed by $1 \times$ $10^{6}$ PBMC in $100 \mu \mathrm{l}$ of flow cytometry buffer (HBSS containing $0.1 \%$ bovine serum albumin, $0.02 \%$ sodium azide). Samples were incubated for 30 minutes at room temperature followed by a wash with flow cytometry buffer and fixation in $1 \%$ formaldehyde. Samples were run on a BD FACSCalibur flow cytometer that was set to acquire 30,000 $\mathrm{CD}^{+} \mathrm{T}$ cells. Analysis was performed using CellQuest software (BD Biosciences, San Jose, CA) and gating was done to accept $\mathrm{CD} 8^{+} /$tetramer $^{+}$cells and to exclude PC5-positive cells.

\section{Cytokine flow cytometry}

CFC assays were performed according to a previously published method [49,50]. $200 \mu \mathrm{l}$ containing $2 \times 10^{6} \mathrm{PBMC}$ in CRPMI-10 medium were plated per well in 96-well round-bottom plates. For cryopreserved PBMC, the thawed cells were then rested at $37^{\circ} \mathrm{C}, 7 \% \mathrm{CO}_{2}$ overnight. For both fresh and cryopreserved PBMC, activation reagents (stimulus + brefeldin A) were added in a volume of $20 \mu \mathrm{l}$ per $200 \mu \mathrm{l}$ of cell suspension per well and the cells were then incubated at $37^{\circ} \mathrm{C}$ for 6 hours. Stimuli included CMV pp65 peptide mix (BD Biosciences; used at a final concentration of $1.7 \mu \mathrm{g} / \mathrm{ml} /$ peptide); CMV pp65 ${ }_{495-503}$ peptide (SynPep Corp., Dublin, CA; used at a final concentration of $10 \mu \mathrm{g} / \mathrm{ml}$ ); and SEB (Sigma; used at a final concentration of $1 \mu \mathrm{g} / \mathrm{ml}$ ). All samples received a final concentration of $1 \mu \mathrm{g} / \mathrm{ml}$ each of CD28+CD49d costimu- latory antibodies and $10 \mu \mathrm{g} / \mathrm{ml}$ of brefeldin A (both from BD Biosciences). After 6 hours incubation, the cells were treated with $2 \mathrm{mM}$ final concentration of EDTA for 15 minutes at room temperature, then fixed with FACS Lysing Solution (BD Biosciences) and stored at $-80^{\circ} \mathrm{C}$. When ready to stain, the frozen plates were thawed at $37^{\circ} \mathrm{C}$ and processed further with FACS Permeabilizing Solution 2 (BD Biosciences) followed by staining with IFN $\gamma$ FITC/ CD69 PE/CD8 PerCPCy5.5/CD3 APC (BD Biosciences) for 1 hour at room temperature. Plates were washed and cells resuspended in 1\% paraformaldehyde in PBS.

Samples were acquired within 24 hours of staining using a FACSCalibur flow cytometer with a Multiwell Autosampler, using Multiwell Plate Manager and CellQuest Pro software (BD Biosciences). 40,000 $\mathrm{CD} 3^{+}{ }^{\mathrm{CD}} 8^{+}$lymphocytes were collected per sample. A "response region" was set around double-positive cells in a gated dot plot displaying CD69 versus IFN $\gamma$ staining from an SEB-stimulated sample. This response region was then applied to all samples to determine the percentage of cytokine-positive cells. Data were reported as the net percent of $\mathrm{CD}^{+}{ }^{+} \mathrm{CD} 8^{+}$ lymphocytes that were IFN $\gamma^{+}$after subtracting the response of unstimulated samples.

\section{ELISPOT}

PBMC were assayed for IFN $\gamma$ production in the presence of CMV pp65 peptide mix (BD Biosciences), SEB, and media in replicates of 6. Multiscreen-HA 96-well plates (Millipore, Bedford, MA) were coated overnight at $4{ }^{\circ} \mathrm{C}$ with $100 \mu \mathrm{l} /$ well of $10 \mu \mathrm{g} / \mathrm{ml}$ mouse anti-human IFN $\gamma$ mAb 7-D1K (diaPharma Group, Inc., West Chester, OH) in Dulbecco's Phosphate Buffered Saline (DPBS) (Gibco Invitrogen). The plates were washed 3 times for 5 minutes each with $150 \mu \mathrm{l}$ DPBS/well and blocked with $150 \mu \mathrm{l} /$ well of RPMI-1640, 10\% human AB serum, 25 mM HEPES, $100 \mathrm{U} / \mathrm{ml}$ penicillin, $100 \mu \mathrm{g} / \mathrm{ml}$ streptomycin, and $2 \mathrm{mM}$ L-glutamine for 1 hour at $37^{\circ} \mathrm{C}$ in $5 \% \mathrm{CO}_{2}$. PBMC were plated at 100,000 per well with 1:800 of CMV pp65 peptide mix (approximately $1.75 \mu \mathrm{g} / \mathrm{ml}$ of each peptide), $100 \mathrm{ng} / \mathrm{ml}$ of SEB, or media in a total volume of $200 \mu \mathrm{l} /$ well for $18-24$ hours at $37^{\circ} \mathrm{C}$ in $5 \% \mathrm{CO}_{2}$.

The plates were washed with $0.05 \%$ Tween/DPBS using a Tecan 96PW plate washer (Tecan, Research Triangle Park, NC). A solution of $100 \mu \mathrm{l}$ of mouse anti-human IFN $\gamma$ biotinylated mAb 7-B6-1 (diaPharma) at $1 \mu \mathrm{g} / \mathrm{ml}$ in DPBS was added to each well and the plates incubated for 2 hours at $37^{\circ} \mathrm{C}, 5 \% \mathrm{CO}_{2}$. Vectastain ABC Peroxidase (Vector Labs, Inc., Burlingame, CA) was added at $100 \mu \mathrm{l} /$ well for 1 hour at room temperature after washing with $0.05 \%$ Tween/DPBS using the Tecan plate washer. The plates were washed for the last time with $0.05 \%$ Tween/DPBS followed by DPBS. Color was developed using $100 \mu \mathrm{l} /$ well of 3-amino-9-ethyl-carbazole [AEC] (Sigma) reconsti- 
tuted in an acetate buffer for 4 minutes at room temperature in the dark. Color development was stopped with deionized water. Basins were removed and the membranes dried overnight in the dark. Membranes were attached to sealing tape (Millipore, Bedford, MA) and the number of spots per well was determined using a KS ELISPOT Automated Reader System with KS ELISPOT 4.2 Software (Carl Zeiss, Inc., Thornwood, NY). The mean number of spots from the six replicate wells at each dilution was reported for each antigen. The analyses in this paper were based on the wells containing $1 \times 10^{5}$ responder PBMC, which is the dilution that yielded the highest ratio of spots/PBMC (data not shown).

\section{Statistical analyses}

All samples tested were included in the analysis, as no attempt was made to exclude outliers. Tests of correlations between fresh and frozen samples were performed using the Pearson Product Moment Correlation Coefficient on the natural logarithm of responses. This transformation was performed to correct for observed skewness in the data, since the statistical test assumes a bivariate normal distribution. However, the significance of the correlations was largely unchanged when untransformed data was used. If the net response equaled zero, a small constant was added (0.004 for $\%$ positive and 1 for cells $/ 10^{5}$ PBMC) prior to computing the natural log. The Wilcoxon Signed-Rank test was performed for differences between paired fresh and frozen samples. Tests of correlations between assays were performed using the Pearson Product Moment Correlation Coefficient after natural logarithmic transformation and adjustment for zeroes.

For each assay and antigen combination, the operating characteristics were summarized in terms of the sensitivity and false positive rate (1-specificity) for cut-off values of net response of both fresh and frozen samples. The sensitivity and false positive rate were defined as the proportion of correctly identified CMV seropositive samples and incorrectly identified seronegative samples, respectively, with an assay response exceeding each cut-off value. The ROC curve was constructed as a plot of the false positive test rate versus sensitivity for all cut-off values in the range of assay responses observed. For each ROC curve, the sensitivity and specificity was reported for the cut-off that maximized specificity subject to the constraint that sensitivity $\geq 90 \%$; or alternatively, if the sensitivity was bounded below $90 \%$, at the specificity corresponding to the maximum sensitivity. Tests for differences in the areas under the ROC curves were performed using the nonparametric test for correlated data of Delong et al [51]. The ROC analysis was performed with Stata version 7 software (StataCorp LP, College Station, TX). All other statistical analyses were performed with SAS version 9 software (SAS Institute, Cary, NC).

\section{Authors' contributions}

HTM wrote the manuscript with input from SAG, DPA, JM, TMC, and TKR. JM and DPA compiled the data and did statistical analysis. SB, JKP, AS, JCC, and CD processed and analyzed the samples. HTM, SAG, VCM, TMC, MAM, HKL, TKR, and MLD planned and supervised the study and all authors reviewed and edited the manuscript

\section{Additional material}

\section{Additional File 1}

Protocol for Isolation, Cryopreservation, and Thawing of PBMC Optimized protocol used in this study for cryopreservation and thawing of PBMC

Click here for file

[http://www.biomedcentral.com/content/supplementary/14712172-6-17-S1.pdf]

\section{Acknowledgements}

This work was supported by Public Health Service grant \#U54 CA908I8 from the National Cancer Institute.

\section{References}

I. Zinkernagel RM, Hengartner $\mathrm{H}$ : On immunity against infections and vaccines: credo 2004. Scand J Immunol 2004, 60(I-2):9-13.

2. McMichael AJ, Hanke T: HIV vaccines 1983-2003. Nat Med 2003, 9(7):874-880.

3. Torresi J, Bharadwaj M, Jackson DC, Gowans EJ: Neutralising antibody, CTL and dendritic cell responses to hepatitis $C$ virus: a preventative vaccine strategy. Curr Drug Targets 2004, 5(I):4I-56.

4. Moorthy VS, Good MF, Hill AV: Malaria vaccine developments. Lancet 2004, 363(9403): I50-I56.

5. Gilboa E: The promise of cancer vaccines. Nat Rev Cancer 2004, 4(5):40I-4II.

6. Disis ML, Maecker HT, Clay TM, Lyerly HK, Chang JCC: Immunologic monitoring to assess immunity to solid tumors. In Measuring immunity: the immunoloic surrogates handbook Edited by: Lotze MT, Thompson AW. London , Academic Press; 2003.

7. Keilholz U, Weber J, Finke JH, Gabrilovich DI, Kast WM, Disis ML, Kirkwood JM, Scheibenbogen C, Schlom J, Maino VC, Lyerly HK, Lee PP, Storkus W, Marincola F, Worobec A, Atkins MB: Immunologic monitoring of cancer vaccine therapy: results of a workshop sponsored by the Society for Biological Therapy. J Immunother 2002, 25(2):97-138.

8. Coulie PG, van der Bruggen P: T-cell responses of vaccinated cancer patients. Curr Opin Immunol 2003, I5(2): $131-137$.

9. Maecker HT: The role of immune monitoring in evaluating cancer immunotherapy. In Immunotherapy of Cancer Edited by: Disis ML. Totowa, NJ , Humana Press; 2005.

10. Maecker HT, Maino VC: T cell immunity to HIV: defining parameters of protection. Current HIV Research 2003, I:249-259.

II. Belli F, Testori A, Rivoltini L, Maio M, Andreola G, Sertoli MR, Gallino G, Piris A, Cattelan A, Lazzari I, Carrabba M, Scita G, Santantonio C, Pilla L, Tragni G, Lombardo C, Arienti F, Marchiano A, Queirolo P, Bertolini F, Cova A, Lamaj E, Ascani L, Camerini R, Corsi M, Cascinelli N, Lewis JJ, Srivastava P, Parmiani G: Vaccination of metastatic melanoma patients with autologous tumor-derived heat shock protein gp96-peptide complexes: clinical and immunologic findings. J Clin Oncol 2002, 20(20):4|69-4| 80.

12. Sun P, Schwenk R, White K, Stoute JA, Cohen J, Ballou WR, Voss G, Kester KE, Heppner DG, Krzych U: Protective immunity induced with malaria vaccine, RTS,S, is linked to Plasmodium falciparum circumsporozoite protein-specific CD4(+) and CD8(+) T cells producing IFN-gamma. J Immunol 2003, I7 I(I2):696|-6967. 
13. Perez-Diez A, Spiess PJ, Restifo NP, Matzinger P, Marincola FM: Intensity of the vaccine-elicited immune response determines tumor clearance. J Immunol 2002, I68(I):338-347.

14. Gurunathan S, Prussin C, Sacks DL, Seder RA: Vaccine requirements for sustained cellular immunity to an intracellular parasitic infection. Nat Med 1998, 4(I 2): 1409-1415.

15. Gurunathan S, Stobie L, Prussin C, Sacks DL, Glaichenhaus N, Fowell DJ, Locksley RM, Chang JT, Wu CY, Seder RA: Requirements for the maintenance of Thl immunity in vivo following DNA vaccination: a potential immunoregulatory role for $C D 8+T$ cells. J Immunol 2000, 165(2):915-924.

16. Stobie L, Gurunathan S, Prussin C, Sacks DL, Glaichenhaus N, Wu CY, Seder RA: The role of antigen and IL- I 2 in sustaining Th I memory cells in vivo: IL- $I 2$ is required to maintain memory $/$ effector ThI cells sufficient to mediate protection to an infectious parasite challenge. Proc Natl Acad Sci U S A 2000, 97( I 5):8427-8432.

17. Mendez S, Gurunathan S, Kamhawi S, Belkaid Y, Moga MA, Skeiky YA Campos-Neto A, Reed S, Seder RA, Sacks D: The potency and durability of DNA- and protein-based vaccines against Leishmania major evaluated using low-dose, intraderma challenge. J Immunol 200I, 166(8):5 I 22-5I 28.

18. Gehrz RC, Knorr SO: Characterization of the role of mononuclear cell subpopulations in the in vitro lymphocyte proliferation assay. Clin Exp Immunol 1979, 37(3):55 I-557.

19. McCoy JL, Herberman RB, Rosenberg EB, Donnelly FC, Levine PH, Alford C: 5 I Chromium-release assay for cell-mediated cytotoxicity of human leukemia and lymphoid tissue-culture cells. Natl Cancer Inst Monogr 1973, 37:59-67.

20. Altman JD, Moss PAH, Goulder PJR, Barouch DH, McHeyzer-Williams MG, Bell JI, McMichael AJ, Davis MM: Phenotypic analysis of antigen-specific T lymphocytes. In Science Volume 274. Issue 5284 UNITED STATES ; 1996:94-96.

21. Waldrop SL, Pitcher CJ, Peterson DM, Maino VC, Picker LJ: Determination of antigen-specific memory/effector CD4+ $T$ cell frequencies by flow cytometry: evidence for a novel, antigenspecific homeostatic mechanism in HIV-associated immunodeficiency. In J Clin Invest Volume 99. Issue 7 UNITED STATES ; 1997:1739-1750

22. Suni MA, Picker LJ, Maino VC: Detection of antigen-specific $\mathbf{T}$ cell cytokine expression in whole blood by flow cytometry. In J Immunol Methods Volume 2 I 2. Issue I NETHERLANDS; 1998:89-98.

23. Czerkinsky C, Andersson G, Ekre HP, Nilsson LA, Klareskog L, Ouchterlony O: Reverse ELISPOT assay for clonal analysis of cytokine production. I. Enumeration of gamma-interferonsecreting cells. J Immunol Methods I988, I I O(I):29-36.

24. Kuzushima K, Hoshino Y, Fujii K, Yokoyama N, Fujita M, Kiyono T, Kimura H, Morishima T, Morishima Y, Tsurumi T: Rapid determination of Epstein-Barr virus-specific CD8(+) T-cell frequencies by flow cytometry. Blood 1999, 94(9):3094-3100.

25. Moretto WJ, Drohan LA, Nixon DF: Rapid quantification of SIV specific CD8 T cell responses with recombinant vaccinia virus ELISPOT or cytokine flow cytometry. Aids 2000 I 4(16):2625-2627.

26. Asemissen AM, Nagorsen D, Keilholz U, Letsch A, Schmittel A, Thiel E, Scheibenbogen C: Flow cytometric determination of intracellular or secreted IFNgamma for the quantification of antigen reactive T cells. J Immunol Methods 200I, 25 I (I-2): I0I-108.

27. Pahar B, Li J, Rourke T, Miller CJ, McChesney MB: Detection of antigen-specific $T$ cell interferon gamma expression by ELISPOT and cytokine flow cytometry assays in rhesus macaques. J Immunol Methods 2003, 282(I-2): I03-II 5.

28. Whiteside TL, Zhao Y, Tsukishiro T, Elder EM, Gooding W, Baar J: Enzyme-linked immunospot, cytokine flow cytometry, and tetramers in the detection of T-cell responses to a dendritic cell-based multipeptide vaccine in patients with melanoma. Clin Cancer Res 2003, 9(2):64I-649.

29. Karlsson AC, Martin JN, Younger SR, Bredt BM, Epling L, Ronquillo R, Varma A, Deeks SG, McCune JM, Nixon DF, Sinclair E: Comparison of the ELISPOT and cytokine flow cytometry assays for the enumeration of antigen-specific $\mathbf{T}$ cells. J Immunol Methods 2003, 283(I-2): $|4|-\mid 53$.

30. Heeger PS, Greenspan NS, Kuhlenschmidt S, Dejelo C, Hricik DE Schulak JA, Tary-Lehmann M: Pretransplant frequency of donorspecific, IFN-gamma-producing lymphocytes is a manifestation of immunologic memory and correlates with the risk of posttransplant rejection episodes. I Immunol 1999 , 163(4):2267-2275.

31. Helms T, Boehm BO, Asaad RJ, Trezza RP, Lehmann PV, Tary-Lehmann M: Direct visualization of cytokine-producing recall antigen-specific CD4 memory $T$ cells in healthy individuals and HIV patients. J Immunol 2000, I 64(7):3723-3732.

32. Oldham RK, Dean JH, Cannon GB, Ortaldo JR, Dunston G, Applebaum F, McCoy JL, Djeu J, Herberman RB: Cryopreservation of human lymphocyte function as measured by in vitro assays. Int J Cancer 1976, I8(2): 145-I55.

33. Weinberg A, Wohl DA, Brown DG, Pott GB, Zhang L, Ray MG, van der Horst C: Effect of cryopreservation on measurement of cytomegalovirus-specific cellular immune responses in HIVinfected patients. J Acquir Immune Defic Syndr 2000, 25(2): I $09-$ I I 4.

34. Costantini A, Mancini S, Giuliodoro S, Butini L, Regnery CM, Silvestri G, Montroni M: Effects of cryopreservation on lymphocyte immunophenotype and function. J Immunol Methods 2003, 278(I-2): | $45-\mid 55$.

35. Weinberg A, Betensky RA, Zhang L, Ray G: Effect of shipment, storage, anticoagulant, and cell separation on lymphocyte proliferation assays for human immunodeficiency virusinfected patients. Clin Diagn Lab Immunol 1998, 5(6):804-807.

36. Maecker HT, Dunn HS, Suni MA, Khatamzas E, Pitcher CJ, Bunde T, Persaud N, Trigona W, Fu TM, Sinclair E, Bredt BM, McCune JM, Maino VC, Kern F, Picker LJ: Use of overlapping peptide mixtures as antigens for cytokine flow cytometry. I Immunol Methods 200I, 255(I-2):27-40.

37. Weinberg A, Zhang L, Brown D, Erice A, Polsky B, Hirsch MS, Owens $\mathrm{S}$, Lamb K: Viability and functional activity of cryopreserved mononuclear cells. Clin Diagn Lab Immunol 2000, 7(4):7|4-7|6.

38. Kleeberger CA, Lyles RH, Margolick JB, Rinaldo CR, Phair JP, Giorgi $\mathrm{JV}$ : Viability and recovery of peripheral blood mononuclear cells cryopreserved for up to 12 years in a multicenter study. Clin Diagn Lab Immunol 1999, 6(I):14-19.

39. Kreher CR, Dittrich MT, Guerkov R, Boehm BO, Tary-Lehmann M: CD4+ and CD8+ cells in cryopreserved human PBMC maintain full functionality in cytokine ELISPOT assays. I Immunol Methods 2003, 278(I-2):79-93.

40. Smith JG, Liu X, Kaufhold RM, Clair J, Caulfield MJ: Development and validation of a gamma interferon ELISPOT assay for quantitation of cellular immune responses to varicellazoster virus. Clin Diagn Lab Immunol 200I, 8(5):87I-879.

41. Gebauer BS, Hricik DE, Atallah A, Bryan K, Riley J, Tary-Lehmann M, Greenspan NS, Dejelo C, Boehm BO, Hering BJ, Heeger PS: Evolution of the enzyme-linked immunosorbent spot assay for post-transplant alloreactivity as a potentially useful immune monitoring tool. Am J Transplant 2002, 2(9):857-866.

42. Sobota V, Bubenik J, Indrova M, Vlk V, Jakoubkova J: Use of cryopreserved lymphocytes for assessment of the immunological effects of interferon therapy in renal cell carcinoma patients. J Immunol Methods 1997, 203(1): I-10.

43. Ott PA, Berner BR, Herzog BA, Guerkov R, Yonkers NL, DurinovicBello I, Tary-Lehmann M, Lehmann PV, Anthony DD: CD28 costimulation enhances the sensitivity of the ELISPOT assay for detection of antigen-specific memory effector CD4 and CD8 cell populations in human diseases. I Immunol Methods 2004, 285(2):223-235.

44. Zhu J, Shearer GM, Marincola FM, Norman JE, Rott D, Zou JP, Epstein SE: Discordant cellular and humoral immune responses to cytomegalovirus infection in healthy blood donors: existence of a Thl-type dominant response. Int Immunol 200I, I3(6):785-790

45. Betts MR, Casazza JP, Patterson BA, Waldrop S, Trigona W, Fu TM, Kern F, Picker LJ, Koup RA: Putative immunodominant human immunodeficiency virus-specific CD8(+) T- cell responses cannot be predicted by major histocompatibility complex class I haplotype. I Virol 2000, 74(19):9|44-9|5I.

46. Ghanekar SA, Nomura LE, Suni MA, Picker LJ, Maecker HT, Maino VC: Gamma interferon expression in CD8(+) $T$ cells is a marker for circulating cytotoxic $T$ lymphocytes that recognize an HLA A2-restricted epitope of human cytomegalovirus phosphoprotein pp65. Clin Diagn Lab Immunol 200I, 8(3):628-631.

47. Dunn HS, Haney DJ, Ghanekar SA, Stepick-Biek P, Lewis DB, Maecker $\mathrm{HT}$ : Dynamics of CD4 and CD8 T cell responses to cytomeg. 
alovirus in healthy human donors. J Infect Dis 2002, 186(I): $15-22$.

48. Hobeika AC, Morse MA, Osada T, Ghanayem M, Niedzwiecki D, Barrier R, Lyerly HK, Clay TM: Enumerating antigen-specific T-cell responses in peripheral blood: a comparison of peptide MHC Tetramer, ELISpot, and intracellular cytokine analysis. J Immunother 2005, 28(I):63-72.

49. Suni MA, Dunn HS, Orr PL, deLaat R, Sinclair E, Ghanekar SA, Bredt BM, Dunne JF, Maino VC, Maecker HT: Performance of platebased cytokine flow cytometry with automated data analysis. BMC Immunology 2003, 4:9.

50. Maecker HT: Cytokine flow cytometry. In Flow Cytometry Protocols 2nd edition. Edited by: Hawley TS, Hawley RG. Totowa, NJ, Humana Press; 2004:95- 107.

5I. DeLong ER, DeLong DM, Clarke-Pearson DL: Comparing the areas under two or more correlated receiver operating characteristic curves: a nonparametric approach. Biometrics 1988, 44(3):837-845.

Publish with Bio Med Central and every scientist can read your work free of charge

"BioMed Central will be the most significant development for disseminating the results of biomedical research in our lifetime. "

Sir Paul Nurse, Cancer Research UK

Your research papers will be:

- available free of charge to the entire biomedical community

- peer reviewed and published immediately upon acceptance

- cited in PubMed and archived on PubMed Central

- yours - you keep the copyright

Submit your manuscript here:

http://www.biomedcentral.com/info/publishing_adv.asp
BioMedcentral 